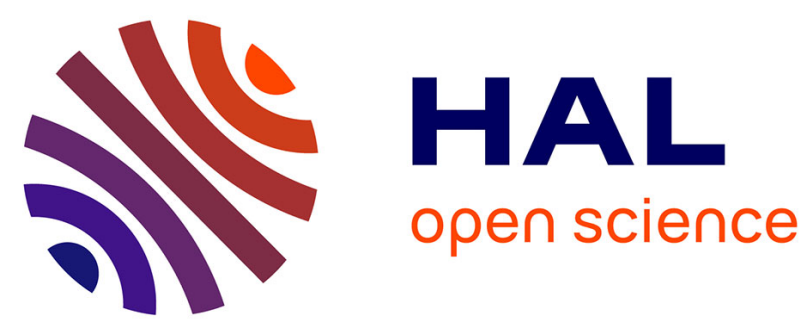

\title{
The Influence of Chemical and Thermal Treatments on the Diss Fiber Hygroscopic Behaviors
}

\author{
Mustapha Nouri, Mahfoud Tahlaiti, Frederic Grondin, Rafik Belarbi
}

\section{To cite this version:}

Mustapha Nouri, Mahfoud Tahlaiti, Frederic Grondin, Rafik Belarbi. The Influence of Chemical and Thermal Treatments on the Diss Fiber Hygroscopic Behaviors. Journal of Natural Fibers, 2020, pp.1-14. 10.1080/15440478.2020.1848733 . hal-03195372

\section{HAL Id: hal-03195372 \\ https://hal.science/hal-03195372}

Submitted on 6 May 2021

HAL is a multi-disciplinary open access archive for the deposit and dissemination of scientific research documents, whether they are published or not. The documents may come from teaching and research institutions in France or abroad, or from public or private research centers.
L'archive ouverte pluridisciplinaire HAL, est destinée au dépôt et à la diffusion de documents scientifiques de niveau recherche, publiés ou non, émanant des établissements d'enseignement et de recherche français ou étrangers, des laboratoires publics ou privés. 


\title{
The Influence of Chemical and Thermal Treatments on the Diss Fiber Hygroscopic Behaviors
}

\author{
Mustapha Nouri ${ }^{\mathrm{a}, \mathrm{b}}$, Mahfoud Tahlaitia, ${ }^{\mathrm{a}, \mathrm{b}}$, Fréderic Grondin ${ }^{\mathrm{b}}$, and Rafik Belarbic \\ anstitut Catholique d'Arts Et Métiers, Carquefou, France; 'nstitut De Recherche En Génie Civil Et Mécanique (Gem), \\ UMR 6183, Centrale De Nantes - Université De Nantes - CNRS, NANTES cedex 3, France; 'Department of Civil \\ Engineering LaSIE, LA Rochelle University, UMR, 7356, CNRS, France
}

\begin{abstract}
Diss fibers, also called Ampelodesmos mauritanicus, are one of the least studied fibers in the literature. Indeed, the rare studies discussed have focused on mechanical and physicochemical properties. The present work deals with hygrothermal characterization and the effect of treatments on their behavior. So, untreated and treated Diss fibers with chemical treat-ments (alkaline, silane, and acetic acid) and heat treatment were character-ized by absorption tests by water immersion and others by water vapor adsorption and desorption (Proumid-SPS). The results found have shown that these fibers presented a type II sorption isotherm with hysteresis where their saturation point could reach up to $40 \%$ of their dry mass. However, the treatments carried out seem to be able to reduce their hydro-philic nature especially after heat, silane, and acetic acid treatments. The adsorption kinetics, on the other hand, also seem to be positively influenced by these treatments, especially after the chemical treatments.
\end{abstract}

\section{KEYWORDS}

Natural fibers; Diss fibers; hygrothermal behavior; chemical treatments; heat treatment

\section{Introduction}

Development of bio-based composites represents one of the sustainability approaches for the industry. The present work aims to explore the characteristics and performance of a natural fiber used as reinforcement of bio-composite. Natural fibers continue to attract high research interest with focus on the prediction of their behavior when exposed to environment to optimize their durability. One of the most important durability aspects of composites is their hygrothermal properties that dictate the insulating behavior. Indeed, the monitoring and quantification of water molecules progress within composite allows the determination of insulating properties. Before discussing the hygro-thermal properties of new bio-based composites, it is necessary to understand the hygrothermal behavior of the natural fibers alone.

The present study explores the design of a bio-composite based on natural fiber extracted from Mauritanian grass, also called Diss or Ampelodesmos mauritanicus. This perennial plant belongs to the family Poaceae rich in fibers (Damerdji 2012). Recently, this plant attracted the attention of researchers and particularly to be used as a reinforcement for cement composites (Merzoud and Habita 2008) (Achour, 
Ghomari, and Belayachi 2017), and polymer composites (Bourahli 2014) (Sarasini et al. 2019). In terms of extraction methods, chemical composition, treatments, mechanical and thermal behavior, Diss fibers have been subject to several studies in the literature (Merzoud and Habita 2008) (Bourahli and Osmani 2013) (Achour, Ghomari, and Belayachi 2017) (Sarasini et al. 2019) (Nouri et al. 2019). However, their hygrothermal properties remain not fully explored by the authors. Merzoud and Habita (2008) determined the water saturation rate of crushed Diss fibers and heat-treated ones with boiling water. The authors obtained saturation rates of $92.38 \%$ and $90.00 \%$ for crushed and heat-treated fibers, respectively. However, Bourahli (2014) obtained only $14 \%$ of saturation rate for untreated Diss fibers. The same author noticed a drop in the saturation rate by $6 \%$ when treating the fibers by alkaline solution. When embedded in composite materials, Achour, Ghomari, and Belayachi (2017) noticed an increase of water absorption in the case of Diss fibers in cement-based mortars. However, alkaline treatment of fibers showed reduced water absorption of the cement mortar Biocomposite.

The sensitivity of natural fibers extracted from plants to water molecules is well established to impact the bio-composite functionality (Azwa et al. 2013). This phenomenon is explained by the free hydroxyl groups present on the fibers surface (Guo et al. 2018). Hemicellulose, pectin, and lignin are the main components containing these hydroxyl groups with variable quantity. Hill, Norton, and Newman (2009) observed a considerable difference in the adsorption/desorption behavior between different natural fibers and explained this by the different chemical composition of these fibers, especially the lignin content. To overcome this challenge, it has been proven that physical and chemical treatments (heating, silane, and acetic acid treatments) reduce the hydrophilic behavior of plant fibers (Bessadok et al. 2008) (Kalia, Kaith, and Kaur 2009) (Alix et al. 2009) (Kabir et al. 2012) (Haque et al. 2015).

In the case of water vapor adsorption at a given temperature, the adsorbed quantities evolution at equilibrium for an adsorbate - adsorbent system at different water activity $\left(\mathrm{a}_{\mathrm{w}}\right)$ is characterized by an adsorption isotherm (Sun et al. 2016). The cellulosic fibers isotherm presents generally a sigmoidal shape with hysteresis between the sorption and desorption loops (Bessadok et al. 2008) (Alix et al. 2009) (Himmel and Mai 2014) (Placet, Day, and Beaugrand 2017) (Guo et al. 2018) (Salmén and Larsson 2018).

Furthermore, there are several mathematical models to describe the cellulosic fibers isotherm, such as, the Guggenheim, Anderson and de Boer (GAB), Generalized D'Arcy and Watt (H-H) and Hailwood and Horrobin (GDW) models (Furmaniak et al. 2007) (Hill, Norton, and Newman 2009) (Alix et al. 2009) (Bui, Labat, and Aubert 2017) (Patcharawijit, Choodum, and Yamsaengsung 2019). Physically, these models describe the fixation of water molecules on the pores surface and can be explained by Langmuir theory (Trabelsi et al. 2011).

In terms of water diffusion kinetics, several authors concluded that water diffuse through these fibers following fick law. (Mannan and Talukder 1997) (Stamboulis, Baillie, and Peijs 2001) (Gouanvé et al. 2007) (Alix et al., 2009) (Bessadok et al. 2009) (Roudier 2012). However, Célino et al. (2013) consider that this behavior is valid only in the case of water vapor adsorption. Langmuir's theory could better describe the diffusion inside the fibers in the case of liquid water absorption during immersion. In addition, Saikia (2010) observed two-stage absorption behaviors for hemp, okra, and betel nut fibers. The first step took place very quickly and obeys Fick's law of diffusion. The second absorption step represents non-fickian diffusion

In this paper, due to lack of studies on the hygro-thermal behavior of Diss fibers in the literature, experimental hygrothermal tests on Diss fibers were performed. The effect of chemical and thermal treatments on their hydrophilicity were studied. This includes alkaline, acidic, and heating at $140^{\circ} \mathrm{C}$ treatments. Both adsorption and desorption were characterized and modeled. The obtained results are of importance to optimize their use for polymer composite materials.

\section{Materials and method}

\section{Diss fibers}

Diss is one of the most abundant plant resources in the Mediterranean contour (Figure 1(a)). In this work, Diss plant leaves were harvested by hand in the north of Algeria at the end of their maturity (in 
2018), then, they went through a manual extraction process according to the method described by (Nouri et al. 2019). These fibers exhibited a low density of $0.93 \mathrm{~g} / \mathrm{cm}^{3}$ with a chemical composition consisting mainly of glucose $(32,6 \%)$, xylan $(24.9 \%)$, and lignin $(20.6 \%)$. They are frequently connected to a part of thorny epidermis, see Figure 1(b), where presented a tensile strength, a Young's modulus, and an ultimate strain of $273 \pm 36 \mathrm{MPa}, 11.4 \pm 2.2 \mathrm{GPa}$, and $2.67 \% \pm 0.6$, respectively. These results are taken from a previous study (Nouri et al. 2019).

\section{Treatment methods}

In order to analyze the effect of the treatment type on the hygrothermal behavior five kind of fibers have been studied: untreated technical Diss fibers (UTFD), treated with $\mathrm{NaOH}$ (NTFD), treated with silane (STFD), treated with acetic acid (ATFD) and thermally treated (TTFD). These fibers are the same used in a previous study (Nouri et al. 2019), treatment methods were carried out as follows:

- The UTFD were submerged in an aqueous solution containing $5 \% \mathrm{NaOH}$ at room temperature during $5 \mathrm{~h}$. Afterward, the NTFD were first cleaned by immersing them in distilled water for $24 \mathrm{~h}$. They were then submerged in a solution of distilled water containing $2 \%$ of acetic acid in order to adjust the $\mathrm{pH}$ to 7 . The $\mathrm{pH}$ degree was measured by a $\mathrm{pH}$ paper indicator. Finally, the NTFD were washed several times with tap water and dried in the oven at $60^{\circ} \mathrm{C}$ for $3 \mathrm{~h}$.

- The UTFD were immersed in an acetic acid solution at room temperature during $90 \mathrm{~min}$. Then, the ATFD were treated with an ethyl acetate solution containing two drops of sulfuric acid to remove excess of acetic acid. Finally, the ATFD were cleaned with tap water and dried in the oven at $40^{\circ} \mathrm{C}$ for $24 \mathrm{~h}$.

- Octyltriethoxysilane (2\%) was dissolved in a mixture of distilled water/ethanol with a volume ratio of $(0.40 / 0.60)$, respectively. This solution was adjusted using acetic acid until the $\mathrm{pH}$ value equaled 4, then the solution was stirred for $2 \mathrm{~h}$. Afterward, the UTFD were submerged in the solution for $2 \mathrm{~h}$ at room temperature. Finally, the STFD were cleaned with tap water and dried in the oven at $60^{\circ} \mathrm{C}$ for $3 \mathrm{~h}$.

- The thermal treatment of UTFD was carried out in an oven at a temperature of $140^{\circ} \mathrm{C}$ during $14 \mathrm{~h}$. Then, the TTFD were cooled down at room temperature.
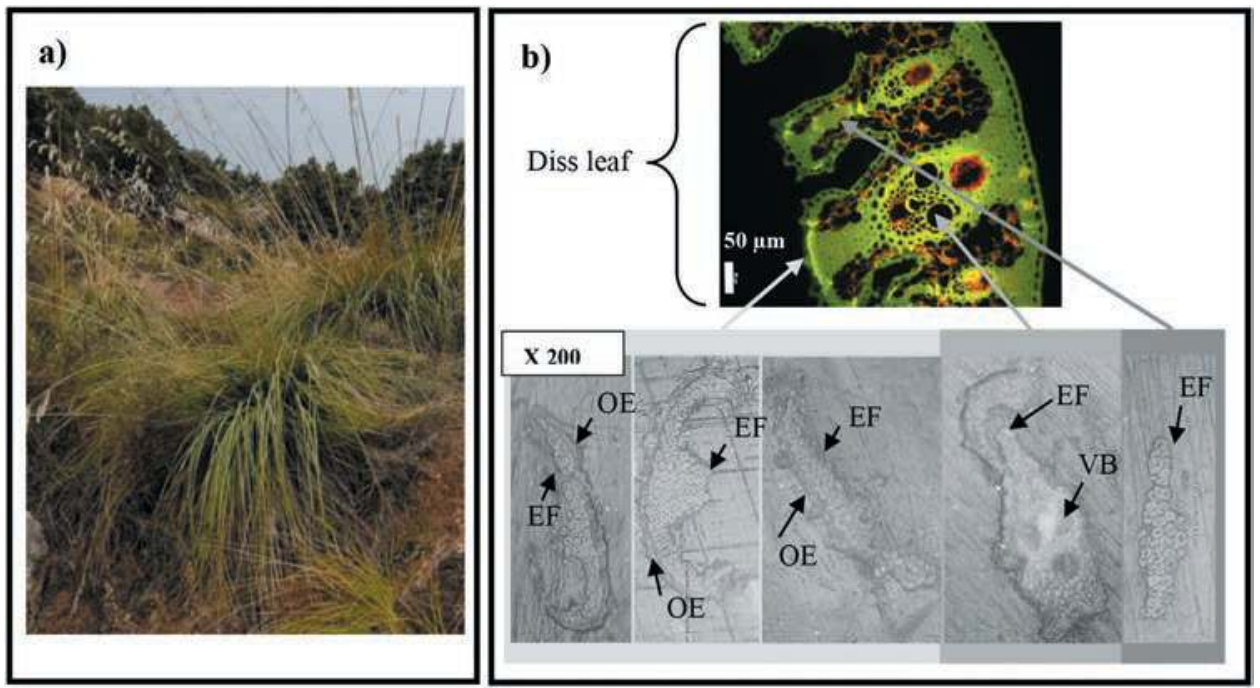

Figure 1. (a) Diss plant. (b) Observation of cross-sections of Diss leaves (treated with Acridine orange) and of UTFD by optical microscope (Nouri et al. 2019). OE: Outer epidermis. EF: Elementary fibers. VB: Vascular bundles. 


\section{Hygrothermal testing methods}

\section{Fourier transform infrared spectroscopy (FTIR)}

FTIR was used in the present study using the Perkin Elmer spectrometer. The spectra were recorded in the wave number range from $4000 \mathrm{~cm}^{-1}$ to $450 \mathrm{~cm}^{-1}$ by Attenuated Total Reflectance (ATR). Before each test, the UTFDs were conditioned in a climatic chamber until equilibrium (to have a stable mass), then tested directly on the device with five independent measurements. Four relative humidity (RH) ranges $(5 \%, 40 \%, 70 \%$, and $90 \%)$ were chosen to study the evolution of these IR spectra with RH.

\section{Water absorption by immersion}

This test consists in drying the untreated and treated Diss fibers. Then, they are immersed in water until saturation by gravimetric method and their water content is measured at different times. The adopted protocol is based on the RILEM recommendation (Amziane et al. 2017). The following adaptations have been considered for Diss fibers

- The test was carried out on approximately $1 \mathrm{~g}$ of fibers

- The sample was dried in a ventilated oven at $60^{\circ} \mathrm{C}$ until mass constancy characterized by a relative change of less than $0.1 \%$ for three consecutive days;

- The sample was left to cool in a desiccator containing silica (previously regenerated) until it was in equilibrium with room temperature $\left(\mathrm{m}_{\mathrm{f} 0}\right)$;

- A plastic filter in bag form, with low water absorption, was also dried and then weighed $\left(\mathrm{m}_{\mathrm{s} 0}\right)$;

- The bag containing the fibers, previously weighed $\left(\mathrm{m}_{\mathrm{fs} 0}\right)$, was subsequently immersed in water for a period of $15 \mathrm{~min}$; then weighed $\left(\mathrm{m}_{\mathrm{fs} 15}\right)$ after being placed in a salad spinner and rotated 100 times with a speed of about $2 \mathrm{rpm}$; that in order to remove the water droplets trapped between the fibers

- This operation was repeated with different immersion times: 15, 30, 60, 120, and $300 \mathrm{~min}$.

- All weightings were carried out using a Sartorius precision balance with $10^{-5} \mathrm{~g}$ resolution. The plastic bags adsorption capacity $\left(\mathrm{w}_{\mathrm{s}}\right)$ as a function of time was also determined using the same protocol. The water absorption rate $\left(\mathrm{w}_{\mathrm{f}}\right)$ as a function of the immersion time $(\mathrm{t})$ was calculated as follows:

$$
w_{f}(t)=\left[\frac{\left(m_{f s}(t)-m_{f s 0}\right)-\left(m_{s 0} \times w_{s}(t)\right)}{m_{f 0}}\right] \times 100
$$

\section{Sorption prüfsystem (Proumid-SPS)}

The water vapor adsorption test has been realized thanks to ProUmid SPS device equipped with an ultra-microbalance recording with precision of $0.1 \mu \mathrm{g}$. The test temperature was kept constant at $23^{\circ} \mathrm{C}$. For the SPS tests, the treated Diss fibers (200-300 mg) were placed in sample holders, then placed in the device at the desired temperature and dried at $0 \% \mathrm{RH}$. Subsequently, the samples were exposed to different $\mathrm{RH}(10 \%, 19 \%, 39 \%, 49 \%, 59 \%, 69 \%, 79 \%, 88 \%$ et $97 \%)$; the transition from one $\mathrm{RH}$ to another is done when the sample reaches equilibrium. Weight monitoring as a function of time was carried out every $10 \mathrm{~min}$ until reaching the equilibrium conditions defined by the following criterion: $(\mathrm{dm} / \mathrm{dt})<0.01 \%$.

The relationship between water activity, $\mathrm{a}_{\mathrm{w}}$ (the ratio between the water vapor pressure at the temperature condition of the sample surface and the saturated water vapor pressure as the same condition of the temperature, which equals $\mathrm{RH}$ when the equilibrium between the sample and the environment is achieved), and the sample equilibrium moisture content (U) at constant temperature has been described by a sorption isotherm. $U$ was defined by the relationship between the wet mass $\left(\mathrm{m}_{\mathrm{w}}\right)$ and the dry mass $\left(\mathrm{m}_{\mathrm{d}}\right)$ of the sample as follows:

$$
U\left(a_{w}\right)=\frac{m_{w}\left(a_{w}\right)-m_{d}}{m_{d}}
$$




\section{Result and discussion}

\section{Adsorption sites identification by FTIR}

Figure 2 represents FTIR spectra of the UTFD conditioned under different RH. These spectra contain important information relating to the moisture absorption process of Diss fibers, which made it possible to identify the adsorption sites in which water molecules have the capacity to create hydrogen bonds (Célino et al. 2014). The spectrum regions most affected by the evolution of $\mathrm{RH}$ are the band between [3600-3100] $\mathrm{cm}^{-1}$ and the peaks at $2917 \mathrm{~cm}-1,2850 \mathrm{~cm}-1,1632 \mathrm{~cm}^{-1}$ and $895 \mathrm{~cm}-1$.

The band [3600-3100] $\mathrm{cm}^{-1}$ represents the hydrogen bonds of the cellulose inter and intramolecular network as well as the hemicellulose-free hydroxyl groups (Célino et al. 2014). With the increase in $\mathrm{RH}$, the intensity of this band increases significantly, therefore signifying the water molecules interaction with $(-\mathrm{OH})$ groups. This band, therefore, represents both the cellulose and hemicellulose macromolecular interactions as well as the water presence in the fibers (Célino et al. 2014). The same observation was raised for the peak at $1635 \mathrm{~cm}^{-1}$ which is due to the water molecule flexural vibration testified to the presence of free water (Guo and $\mathrm{Wu}$ 2017). Moreover, the peaks $2917 \mathrm{~cm}^{-1}$ and $2850 \mathrm{~cm}^{-1}$ also seem to be impacted, corresponding to the stretching vibrations of the $(-\mathrm{CH})$ bonds and of the $\left(-\mathrm{CH}_{2}\right)$ bonds, respectively, present in the cellulose and hemicellulose chains (Célino et al. 2014). However, it is noted that the intensity of the peak at $895 \mathrm{~cm}-1$, characteristic of the cellulose $\beta$ bonds, decreases with increasing humidity. This bond ensures the link between the cellulose monosaccharides, glucose (Bledzki 1999). Such a decrease could be due to a cellulose macromolecule plasticization. Contrary to Célino et al. (2014) results, the peaks at $1735 \mathrm{~cm}^{-1}$ and $1425 \mathrm{~cm}^{-1}$ do not seem to be affected by the variation in RH. They are characteristic of the carboxyl functions of pectin, which should also be affected by the water absorption. This may be due to the low content of pectin in this fiber kind (Nouri et al. 2019). The same constant has been raised for the peak at $1030 \mathrm{~cm}^{-1}$ which is characteristic of the fiber polysaccharide nature (Célino et al. 2014).

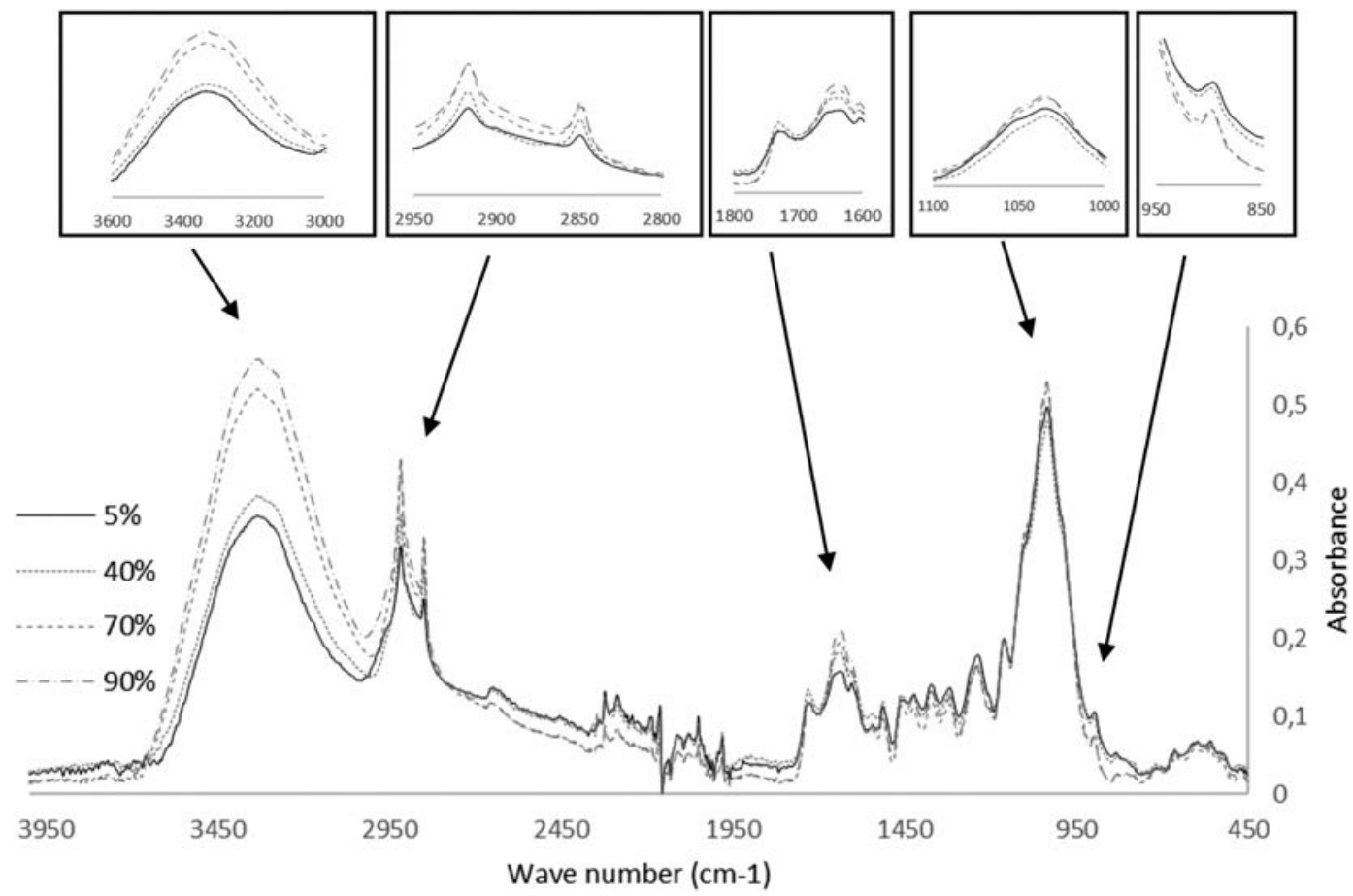

Figure 2. FTIR spectra of UTFD conditioned in environments with different relative humidity. 
In view of these findings, the $(-\mathrm{OH})$ groups could be considered as the main responsible for the Diss fibers water adsorption. This observation has also been raised in several works on cellulosic materials (Guo et al. 2018) (Célino et al. 2014) (Guo and Wu 2017).

\section{Absorption by water immersion}

Figure 3 shows the evolution of the water absorption rate $\left(\mathrm{w}_{\mathrm{f}}\right)$ of treated and untreated Diss fibers as a function of the time square root. At equilibrium, UTFDs and NFTDs exhibited a similar absorption rate of around $40 \%$ of the dry mass. This value seems to be decreasing after the TTFD, STFD, and ATFD treatments by $35 \%, 28 \%$, and $25 \%$, respectively. According to Hill, Norton, and Newman (2009), the sorption capacity increases with the accessibility to the $(-\mathrm{OH})$ groups and the fibers lignin content. This was justified by the lignin network ability to deform to receive the water inside the cell wall. In the case of NTFD, it was concluded in a previous investigation (Nouri et al. 2019) that such treatment significantly degrades pectin and hemicellulose and less effectively lignin. Therefore, this could increase the amount of exposed cellulose leading to increased $(-\mathrm{OH})$ bonds on the surface of the NFTDs, which has also been observed in a previous work (Nouri et al. 2019). However, Placet, Day, and Beaugrand (2017) talked about a compensation effect on retting and not retting hemp fibers. Although the elimination of certain non-cellulosic hydrophilic components during retting, the absorption capacity of these two types of fibers remains similar. In other words, the eliminated absorption sites have been replaced by other unmasked absorption sites. This could be the case for UTFD and NFTD. Other hypotheses are discussed below, following the results of water vapor adsorption and desorption tests.

On the other hand, during treatment with acetic acid or silane, the $(-\mathrm{OH})$ groups present on the fibers surface react with the acetyl groups or the alkoxy groups, respectively, modifying the properties of these polymers so that they become more hydrophobic (Kalia, Kaith, and Kaur 2009) (Kabir et al. 2012). It was also proven that these treatments decrease the surface energy of plant fibers and consequently their absorption rate (Bessadok et al. 2008) (Alix et al. 2009) (Bessadok et al. 2007). Haque et al. (2015) observed a decrease in sisal fibers moisture absorption treated with silane. Furthermore, a more or less similar reduction in the water absorption rate of palm oil fibers treated with silane and acetic acid has been reported by Sreekala and Thomas (2003). In turn, heat treatment consists of reducing the hydroxyl groups number exposed on the fibers surface by degrading certain non-cellulosic components (Ariawan et al. 2018). In addition, this treatment also increases the cellulose crystallinity indices (Rong et al. 2001), therefore, a decrease in accessible cellulose hydroxyl groups. Indeed, at high temperatures, some component of the vegetable fibers softens, in particular hemicellulose, lignin, and may be also the least ordered parts of the cellulose (Salmén and Larsson

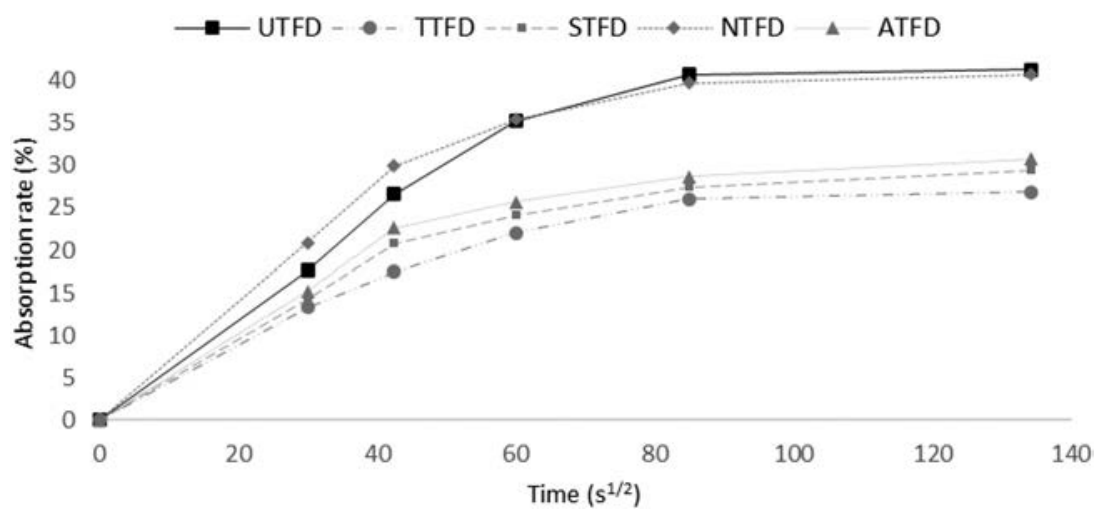

Figure 3. Water absorption curves of treated and untreated Diss fibers. 
2018). Therefore, the intermolecular bonds between hydroxyl groups within the cellulosic structure could arrange, producing a more stable structure with less accessible $(-\mathrm{OH})$ groups.

\section{Sorption isotherm}

Figure 4 shows the sorption-desorption isotherms of the treated Diss fibers. These fibers have a sorption isotherm type II with an $\mathrm{H} 3$ type hysteresis, according to the IUPAC classification (Thommes et al. 2015). This hysteresis is present across the full range of $\mathrm{a}_{\mathrm{w}}$ studied for the various isotherms. The same observations have been raised in several studies on bio-based materials (Kohler et al. 2003) (Bessadok et al. 2008) (Alix et al. 2009) (Himmel and Mai 2014) (Placet, Day, and Beaugrand 2017). The origin of this phenomenon is not yet fully understood. It is still a subject of debate in the literature. Capillary condensation, swelling, glass transition of the matrix, pore effects, and the presence of certain amorphous components like lignin are the main suggestions for the presence of this loop (Kachrimanis et al. 2006) (Hill, Norton, and Newman 2009) (Keating et al. 2013) (Shi and Avramidis 2017) (Fredriksson and Thybring 2018) (Salmén and Larsson 2018) (LaborelPréneron, Magniont, and Aubert 2018).

At $\mathrm{a}_{\mathrm{w}}$ values less than 0.75 , similar behavior was observed on all of the adsorption isotherms. Beyond this value, the adsorption capacity of NTFD becomes more and more superior than that of other treated Diss fibers. At $\mathrm{a}_{\mathrm{w}}$ of 0.97 the NTFDs contain the highest water content (34\%), followed by other treatments that have more or less the same adsorption capacity (around 27\%). These results are similar to those observed in the water absorption test for these fibers

The difference between the NFTD adsorption isotherm and those of other treatments could be attributed, as mentioned earlier, to the presence of additional adsorption sites on the NFTD surface. However, these adsorption sites do not appear to participate in the adsorption process at $\mathrm{RH}$ below $75 \%$, but they are gradually "activated" above this limit. Similar findings have been raised by Kachrimanis et al. (2006) on silicified microcrystalline cellulose. The nature of these sites will be discussed in the next section.

In addition, the shape of the isotherm also provides information on the adsorbent microstructure and the adsorption process and the water molecules fixation method on the portal scale. This type of isotherm is present in the case of non-porous or macroporous materials (greater than $50 \mu \mathrm{m}$ ) which are characterized by unrestricted monolayer-multilayer adsorption (Thommes et al. 2015). At low $\mathrm{a}_{\mathrm{w}}$ the water vapor adsorption takes place gradually until the constitution of the first layer (monolayer) which covers the fibers surface (Langmuir type adsorption). This stage is represented by a point of reflection on the isothermal curve. Beyond this value, multi-layer absorption begins (Henry's type

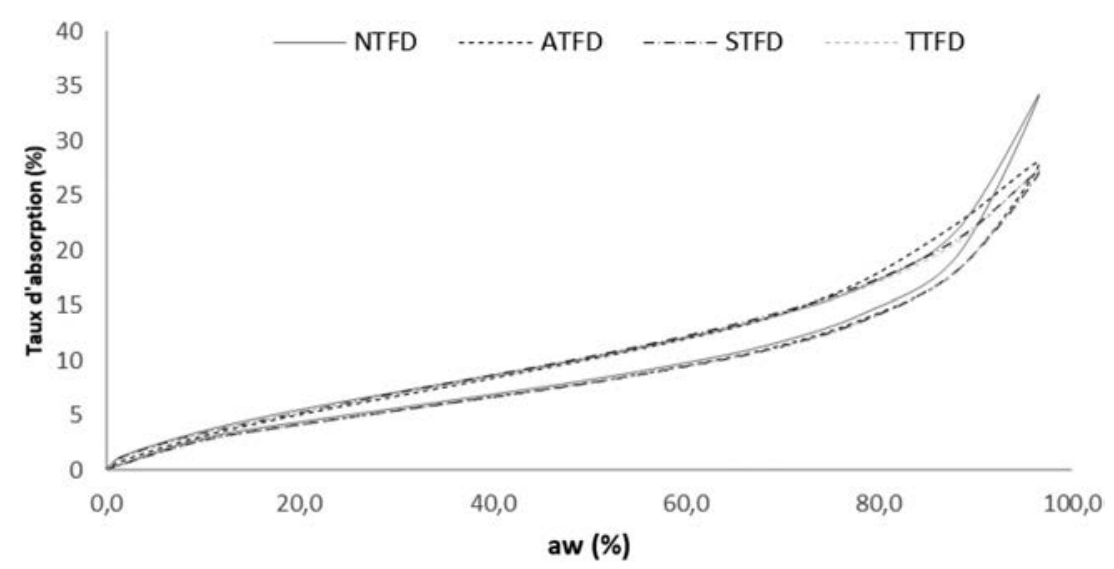

Figure 4. Adsorption-desorption isotherm of treated Diss fibers. 
adsorption). This phase is represented by the linear zone on the isotherm, at high $\mathrm{a}_{\mathrm{w}}$, the curve is close to a vertical asymptote, the thickness of the multilayers is large enough to trigger a water vapor liquefaction due to capillary condensation in the fibers pores (Placet, Day, and Beaugrand 2017) (Laborel-Préneron, Magniont, and Aubert 2018). These findings were also confirmed by Guo and Wu (2017) (Guo et al. 2018) by micro-FTIR.

\section{Mathematical models}

\section{Adsorption isotherm models}

In order to better interpret the adsorption isotherms obtained and better understand the treatments effect on the Diss fibers hygroscopic behavior, three mathematical models were applied to describe these isotherms: GAB, GDW, and H-H (Table 1).

Each adsorption site can only adsorb one water molecule. These adsorbed molecules could subsequently be secondary adsorption sites for the following molecules (Furmaniak et al. 2007). The GDW model assumes that some of these sites have possibilities to become secondary adsorption sites. In turn, the $\mathrm{H}-\mathrm{H}$ model considers that the water adsorbed by the cell wall can exist in two forms: multilayer water $\left(M_{d}\right)$ and monolayer water $\left(M_{h}\right)$ (Patcharawijit, Choodum, and Yamsaengsung 2019). However, although the monolayer in the GAB and DGW model is invariant, that described in the $\mathrm{H}-\mathrm{H}$ model can change across the HR range (Hill, Norton, and Newman 2009).

The quality of the fit was assessed by (Trabelsi et al. 2011) based on two performance criteria (PC): the correlation coefficien $\left(\mathrm{R}^{2}\right)$ and the Model Selection Criterion (MSC). The first translates the variance explained by the model, while the second considers the number of model input parameters and the tests performed number (the higher this criterion, the more efficien the model). The correlation coefficien is calculated as follows:

$$
\mathrm{R}^{2}=1-\frac{\sum_{\mathrm{i}}\left(\mathrm{U}_{\mathrm{i}}-\widehat{\mathrm{U}}_{\mathrm{i}}\right)^{2}}{\sum_{\mathrm{i}}\left(\mathrm{U}_{\mathrm{i}}-\overline{\mathrm{U}}\right)^{2}}
$$

where $U_{i}$ represents the water content of the $\mathrm{i}^{\mathrm{th}}$ experimental measurement, $\hat{\mathrm{U}}_{\mathrm{i}}$ the theoretical water content and $\bar{U}$ the average of the observed water contents.

And the Model Selection Criterion is calculated as follows:

$$
\operatorname{MSC}=\ln \left(\frac{1}{\left(1-\mathrm{R}^{2}\right.}\right)-\frac{2 \lambda}{\mathrm{d}}
$$

where $\lambda$ represents the model parameters number and $d$ the experimental data number.

Table 2 presents the MSC values as well as models' parameters. It is considered that $R^{2}$ coefficien of each model is close to 1 ; this means an excellent correlation of the three models with the experimental results (Figure 5). On the other hand, the GDW model presents the highest MSC value followed by that of the $\mathrm{H}-\mathrm{H}$ model then GAB. And this is valid for the four isotherms. It means that the GDW model is the most adequate with the experimental results.

\begin{tabular}{|c|c|c|}
\hline $\begin{array}{l}\text { Guggenheim, } \\
\text { Anderson and } \\
\text { de Boer (GAB). }\end{array}$ & & $\begin{array}{l}\mathrm{m}_{0} \text { the adsorption capacity in the first layer in } \\
\text { contact with the solid, } \mathrm{c} \text { and } \mathrm{k} \text { are parameters } \\
\text { related to the sorption enthalpy. }\end{array}$ \\
\hline $\begin{array}{l}\text { Generalized } \\
\text { D'Arcy and } \\
\text { Watt (GDW). } \\
\text { Hailwood and } \\
\text { Horrobin } \\
\text { (HH) model. }\end{array}$ & $\begin{array}{c}U_{G D W}\left(a_{W}\right)=\frac{k m_{0} a_{w}}{1+k a_{W}} \frac{1-k(1-\omega) a_{W}}{1-k a_{W}} \\
U_{H-H}\left(a_{W}\right)=\frac{18}{W}\left(\frac{K_{1} K_{2} a_{W}}{1+K_{1} K_{2} a_{W}}\right)+\frac{18}{W}\left(\frac{K_{2} a_{W}}{1+K_{2} a_{w}}\right) U_{H-H}\left(a_{w}\right)=M_{h}+M_{d}\end{array}$ & $\begin{array}{c}\omega \text { represents the molecules adsorbed rate on } \\
\text { primary sites which transform into } \\
\text { secondary adsorption sites. } \\
W \text { is the molecular the dry fiber weight per } \\
\text { mole of sorption sites, } K_{1} \text { and } K_{2} \text { are } \\
\text { constants. }\end{array}$ \\
\hline
\end{tabular}

Table 1. Definition of the mathematical models used. 
Table 2. PC values and models parameters.

\begin{tabular}{ccccccccccccccc}
\hline \multicolumn{1}{c}{ H-H model } & \multicolumn{3}{c}{ GAB model } & \multicolumn{4}{c}{ GDW model } \\
\hline & PC & \multicolumn{3}{c}{ Parameters } & & PC & \multicolumn{3}{c}{ Parameters } & PC & \multicolumn{3}{c}{ Parameters } \\
\hline & $M S C$ & $K_{1}$ & $K_{2}$ & $W$ & $M_{h} \max$ & $M S C$ & $m_{0}\left(g \cdot g^{-1}\right)$ & $C B E T$ & $k$ & $M S C$ & $m_{0}\left(g \cdot g^{-1}\right)$ & $K$ & $k$ & $\omega$ \\
TFD & 5.77 & 13.37 & 0.860 & 387.74 & 0.043 & 5.77 & 0.046 & 14.37 & 0.86 & 8.51 & 0.093 & 3.40 & 0.91 & 0,41 \\
STFD & 5.89 & 13.23 & 0.857 & 382.91 & 0.043 & 5.89 & 0.047 & 14.23 & 0.86 & 8.69 & 0.091 & 3.61 & 0.90 & 0,43 \\
ATFD & 6.10 & 13.92 & 0.863 & 387.17 & 0.043 & 5.84 & 0.046 & 14.92 & 0.86 & 8.12 & 0.109 & 2.73 & 0.92 & 0,33 \\
NTFD & 4.87 & 24.95 & 0.905 & 422.01 & 0.041 & 4.52 & 0.047 & 13.63 & 0.89 & 7.83 & 0.108 & 3.00 & 0.95 & 0,29 \\
\hline
\end{tabular}
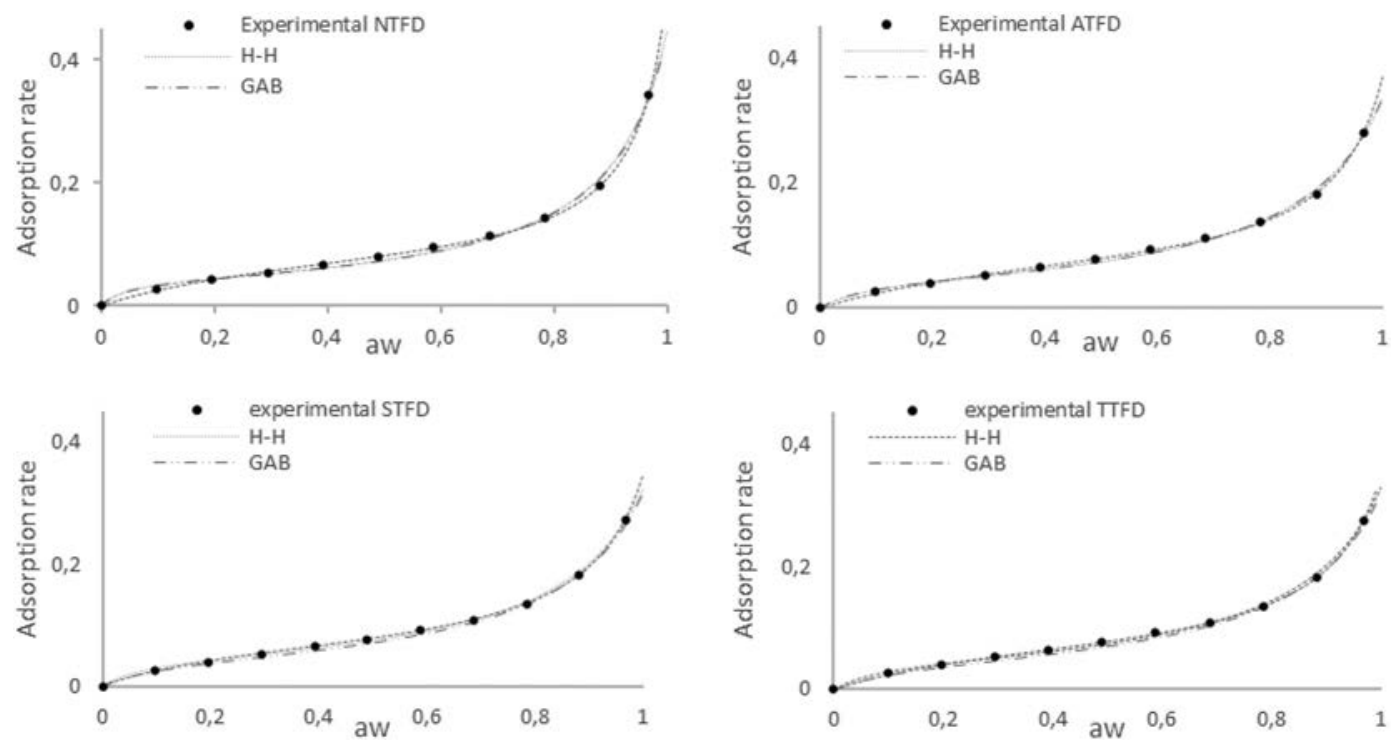

Figure 5. Sorption isotherms of treated Diss fibers from different mathematical models.

The three models provide also information on the monolayer adsorption capacity: $\mathrm{m}_{0}$ for $\mathrm{GAB}$ and GDW models, and $\mathrm{M}_{\mathrm{h}}$ for the $\mathrm{H}-\mathrm{H}$ model (Table 2). $\mathrm{m}_{\mathrm{w}}$ varies as a function of $\mathrm{a}_{\mathrm{w}}$ and reaches its maximum value at $\mathrm{a}_{\mathrm{w}}=1$. This value is, more or less, similar to $\mathrm{m}_{0 \mathrm{GAB}}$. For the GDW model, $\mathrm{m}_{0 \mathrm{GDW}}$ is two times these values and it is observed that between $30 \%$ and $40 \%$ depends on the $\omega_{\text {GDw }}$ parameter of the isotherm, which can become secondary adsorption sites. These observations are valid for the four isotherms.

Figure 6 shows that when $\mathrm{a}_{\mathrm{w}}$ is less than $0.7, \mathrm{M}_{\mathrm{h}}$ of the different fibers exhibits the same behavior. Beyond this value, $M_{h}$ of the NFTDs increases significantly compared to those of the other fibers. In this range of $\mathrm{a}_{\mathrm{w}}$, adsorption by capillary condensation is favored. After such treatment, the presence of micropores on the cell walls of NFTD is highly likely (Shi and Avramidis 2017). Therefore, higher capillary condensation adsorption is observed. Along the same lines, Fouchal et al. (2015) noticed, during their study on extruded earth bricks, that capillary condensation could occur in pores smaller than $0.1 \mu \mathrm{m}$ when $\mathrm{a}_{\mathrm{w}}$ is greater than 0.5 . This could justify the adsorption mechanisms of liquid water and water vapor for the NFTDs observed and discussed previously.

Table 3 presents the fibers saturation point (FSP) of the various treated, experimentally by the water adsorption test as well as by the mathematical models deployed at $\mathrm{a}_{\mathrm{w}}=1 \mathrm{H}-\mathrm{H}$ and GAB models show more or less similar results and comparable to the FSP values determined by the water adsorption test, while the FSP determined by the DGW models are overestimated. These results show a good agreement of the measurement results obtained by two different methods. This highlighted the reliability of the experimental protocol adopted in this work for the water adsorption tests of plant fibers 


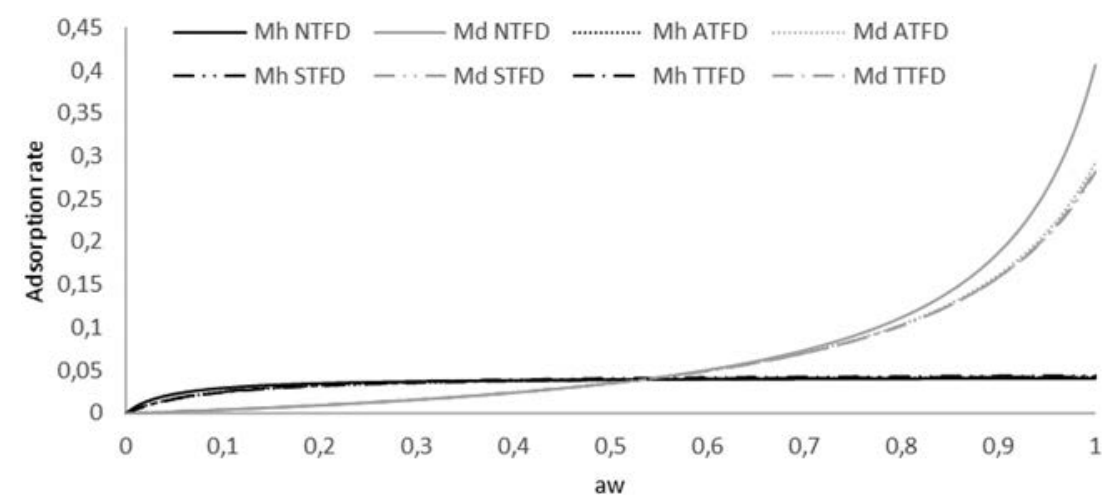

Figure 6. Evolution of the $\mathrm{H}-\mathrm{H}$ model parameters of the treated fibers.

Table 3. FSP of the treated Diss fibers.

\begin{tabular}{lcccc}
\hline & TTFD & STFD & ATFD & NTFD \\
\hline Experimental & 26.8 & 29.4 & 31.2 & 40.7 \\
Modèle GDW & 35.0 & 34.5 & 36.8 & 52.7 \\
Modèle H-H & 32.7 & 32.5 & 33.6 & 44.7 \\
Modèle GAB & 32.1 & 31.7 & 33.6 & 44.7 \\
\hline
\end{tabular}

\section{Sorption kinetic model}

In order to determine the sorption kinetics of the different Diss fibers, the use of Fick's second $1 \mathrm{a}_{\mathrm{w}}$ translating kinetics governed by diffusion has been applied according to the simplest approach used by Gouanvé et al. (2007). The Diss fibers shape was assumed to be a full cylindrical (with $r \ll$ length) and homogeneous represented by their average diameter given by Nouri et al. (2019). The diffusion coefficien could be determined on two parts of the diffusion process, one at the beginning, and the other at the end of the sorption.

At short times, when $\mathrm{M}_{\mathrm{t}} / \mathrm{M}_{\mathrm{eq}}<0.2$ (Mt is the mass adsorbed at time $\mathrm{t}, \mathrm{M}_{\mathrm{eq}}$ is the mass adsorbed at equilibrium at a given $\left.a_{w}\right)$, a linear regression was performed from the curve $\left(M t / M_{e q}\right)^{2}=f\left(t-t_{d}\right)$, whose td is a gap time which represents the time necessary for $\mathrm{a}_{\mathrm{w}}$ to reach equilibrium when it goes from state $a_{w}(i-1)$ to $a_{w}$ (i) (Gouanvé et al. 2007). The slope $k_{1}$ is linked to the water diffusion coefficien $D_{1}$ by the following relationship:

$$
\mathrm{D}_{1}=\frac{\mathrm{k}_{1} \pi \mathrm{r}^{2}}{16}
$$

When $0.7<\mathrm{Mt} / \mathrm{Meq}<0.95$, the water diffusion coefficien $\mathrm{D}_{2}$ can be determined by the following equation:

$$
\mathrm{D}_{2}=-\frac{\mathrm{k}_{2} \mathrm{r}^{2}}{\alpha_{1}^{2}}
$$

where $\propto_{1}$ is a constant coefficien $\left(\propto_{1}=2.40483\right)$, $\mathrm{r}$ is the fibers radius and $\mathrm{k}_{2}$ represents the slope of the curve: $\ln \left(1-\frac{M_{t}}{M_{e q}}\right)=f(t)$

Figure 7 shows the variations of $\mathrm{D}_{1}$ and $\mathrm{D}_{2}$ as a function of $\mathrm{a}_{\mathrm{w}}$ in a semi-logarithmic scale: $\log (\mathrm{D})=\mathrm{f}$ $\left(a_{w}\right)$. A decrease of $D\left(D_{1}, D_{2}\right)$ has been observed when $a_{w}$ increases. This behavior appears to be different from that observed by Gouanvé et al. (2007) and Alix et al. (2009) on different vegetable fibers. Gouanvé et al. (2007) observed an increase in $\mathrm{D}_{1}$ and $\mathrm{D}_{2}$ in flax fibers when $\mathrm{a}_{\mathrm{w}}$ is less than 0.50 ; beyond this value, a decrease in these coefficient was observed. These findings have been explained by the dual mode of sorption (Langmuir and Henry) with swelling effect at high value of $\mathrm{a}_{\mathrm{w}}$. For their part, Alix et al. (2009) 

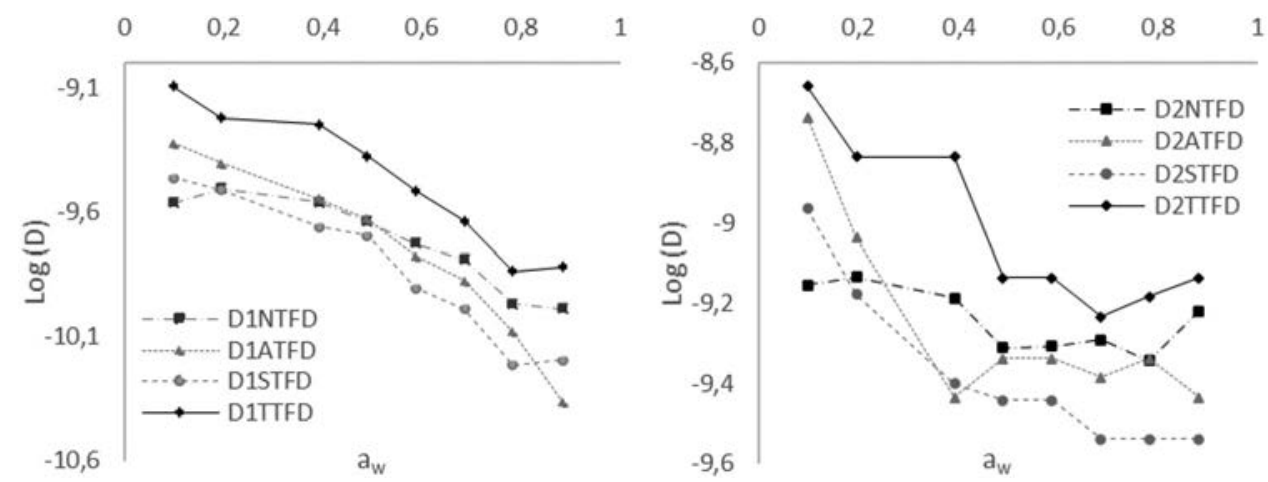

Figure 7. Variations of $D_{1}$ and $D_{2}$ as a function of aw in a semi-logarithmic scale.

observed somewhat similar behavior with a decrease in $\mathrm{D}$ when $\mathrm{a}_{\mathrm{w}}$ is less than 0.1 ; beyond this value, the $\mathrm{D}\left(\mathrm{D}_{1}, \mathrm{D}_{2}\right)$ follows the behavior observed by Gouanvé et al. (2007). This decrease has been explained by the fact that water molecules interact with groups of polar fibers leading to hydrogen bonds. This action increases the cohesion between the cellulosic chains, thus reducing the water mobility. However, the exact knowledge of this diffusion phenomenon remains complicated. The results observed during the present study could be explained by the evolution of the relationship between the adsorption sites and the quantity of adsorbates as well as the accessibility to these sites and the numbers of accesses. Indeed, at low value of $a_{w}$ this ratio is maximum, adsorption will occur by sites that are easy to access. When $a_{w}$ increases this ratio decrease and the sites with easy access will be occupied, which could annoy the water molecules mobility, consequently a decrease in $\mathrm{D}$.

Furthermore, the difference between the two coefficient is significant. The value of $\mathrm{D}_{2}$ was found to be significantly higher than $\mathrm{D}_{1}$. The same observation was raised by Alix et al. (2009) on the different studied plant fibers. This was explained, according to them, by a heterogeneity of the fibers where the surface has a barrier effect with respect to the water diffusion. Consequently, the value $\mathrm{D}_{2}$ (second half-sorption) should be more representative of the water diffusion in the fiber core while $\mathrm{D}_{1}$ (first half-sorption) should be more characteristic of the diffusion through the surface (Alix et al., 2009). On the other hand, the coefficient $\mathrm{D}\left(\mathrm{D}_{1}, \mathrm{D}_{2}\right)$ of the TTFD are much higher, on the range of $\mathrm{a}_{\mathrm{w}}$ studied, in comparison with the other treatments. This could be due to an additional barrier effect after chemical treatments barrier effect due to the binding of the chemical groups provided by reagents (Alix et al., 2009).

The same observations were raised on the water adsorption results of Diss fibers (Table 4). Values of $\mathrm{D}\left(\mathrm{D}_{1}, \mathrm{D}_{2}\right)$ are in the same order of magnitude as those found by SPS. This confirms once again the reliability of the experimental protocol adopted in this work for the water adsorption tests of Diss fibers

\section{Conclusion}

This work aimed to characterize the hygrothermal behavior of a fiber type, Diss fiber, which is underestimated for use as reinforcement for polymer matrices (bio-composites).

The results obtained showed that the $(-\mathrm{OH})$ group could be considered as the main responsible for the water molecules absorption by Diss fibers

Table 4. Diffusion coefficients of treated and untreated Diss fibers during water adsorption.

\begin{tabular}{lccccc}
\hline & UTFD & TTFD & STFD & ATFD & NTFD \\
\hline$D 1\left(\mathrm{~cm}^{2} \cdot \mathrm{s}^{-1}\right) \cdot 10^{-10}$ & 7.90 & 6.80 & 4.50 & 4.20 & 4.30 \\
$D 2\left(\mathrm{~cm}^{2} \cdot \mathrm{s}^{-1}\right) \cdot 10^{-10}$ & 56.50 & 26.80 & 10.10 & 13.70 & 8.00 \\
\hline
\end{tabular}


Diss fibers presented a type II sorption isotherm with an $\mathrm{H} 3$ type hysteresis present over the range of $\mathrm{a}_{\mathrm{w}}$ studied. The mathematical model of GDW is the most adequate to represent reliably the experimental results.

Heat treatment, acetic acid, and silane have significantly decreased hydrophilicity of the fibers Diss. However, the NFTDs exhibited behavior similar to that of the UTFDs. This has been explained, based on the mathematical model $\mathrm{HH}$ results, by the increase in micropores on the NFTD surface; therefore, it promotes more adsorption by capillary condensation. On the other hand, a reduction in the coefficient $\left(\mathrm{D} 1, \mathrm{D}_{2}\right)$ was clearly observed after the various treatments, especially after the chemical treatments. In addition, the results obtained from the water absorption test and the SPS test showed good agreement of the results.

These new results will allow designing bio-composites by optimizing the hygrothermal risk. Indeed, many applications are expected: building envelops, naval engineering, etc. for these applications, it is necessary to limit the water diffusion or to control it.

\section{Acknowledgments}

This research work has been conducted with the financial support of FEDER-Region Pays de la Loire in the framework of CIPTAP R\&D project.

\section{Funding}

This work was supported by the FEDER-Region Pays de la Loire.

\section{References}

Achour, A., F. Ghomari, and N. Belayachi. 2017. Properties of cementitious mortars reinforced with natural fibers. Journal of Adhesion Science and Technology 31:1938-62.

Alix, S., E. Philippe, A. Bessadok, L. Lebrun, C. Morvan, and S. Marais. 2009. Effect of chemical treatments on water sorption and mechanical properties of flax fibres. Bioresource Technology 100:4742-49.

Amziane, S., F. Collet, M. Lawrence, C. Magniont, V. Picandet, and M. Sonebi. 2017. Recommendation of the RILEM TC 236-BBM: Characterisation testing of hemp shiv to determine the initial water content, water absorption, dry density, particle size distribution and thermal conductivity. Materials and Structures 50:167.

Ariawan, D., M. S. Salim, R. M. Taib, M. Z. A. Thirmizir, and Z. A. M. Ishak. 2018. Interfacial characterisation and mechanical properties of heat treated non-woven kenaf fibre and its reinforced composites. Composite Interfaces 25:187-203.

Azwa, Z. N., B. F. Yousif, A. C. Manalo, and W. Karunasena. 2013. A review on the degradability of polymeric composites based on natural fibres. Materials and Design 47:424-42.

Bessadok, A., D. Langevin, F. Gouanvé, C. Chappey, S. Roudesli, et S. Marais. 2009. Study of water sorption on modified Agave fibres. Carbohydrate Polymers 76:74-85.

Bessadok, A., S. Marais, F. Gouanvé, L. Colasse, I. Zimmerlin, S. Roudesli, and M. Métayer. 2007. Effect of chemical treatments of Alfa (Stipa tenacissima) fibres on water-sorption properties. Composites Science and Technology 67:685-97.

Bessadok, A., S. Marais, S. Roudesli, C. Lixon, and M. Métayer. 2008. Influence of chemical modifications on water-sorption and mechanical properties of Agave fibres. Composites. Part A, Applied Science and Manufacturing 39:29-45.

Bledzki, A. 1999. Composites reinforced with cellulose based fibres. Progress in Polymer Science 24:221-74.

Bourahli, M. E. H. 2014. Caractérisation d'un composite verre/époxy. Sciences, Universite Ferhat Abbas Setif 1, Algeria.

Bourahli, M. E. H., and H. Osmani. 2013. Chemical and mechanical properties of diss (Ampelodesmos mauritanicus) fibers. Journal of Natural Fibers 10:219-32.

Bui, R., M. Labat, and J.-E. Aubert. 2017. Comparison of the saturated salt solution and the dynamic vapor sorption techniques based on the measured sorption isotherm of barley straw. Construction and Building Materials 141:140-51.

Célino, A., O. Gonçalves, F. Jacquemin, and S. Fréour. 2014. Utilisation de la spectrométrie infrarouge pour une quantification rapide du taux d'humidité dans des fibres végétales. Revue des composites et des matériaux avancés 24:81-95. 
Célino, A., S. Fréour, F. Jacquemin, and P. Casari. 2013. Characterization and modeling of the moisture diffusion behavior of natural fibers. Journal of Applied Polymer Science 130:297-306.

Damerdji, A. 2012. Les Orthoptéroïdes sur différentes plantes dans la région de Tlemcen (Algérie). Afrique Science 8:82-92.

Fouchal, F., F. Gouny, P. Maillard, L. Ulmet, and S. Rossignol. 2015. Experimental evaluation of hydric performances of masonry walls made of earth bricks, geopolymer and wooden frame. Building and Environment 87:234-43.

Fredriksson, M., and E. E. Thybring. 2018. Scanning or desorption isotherms? Characterising sorption hysteresis of wood. Cellulose 25:4477-85.

Furmaniak, S., A. P. Terzyk, P. A. Gauden, and G. Rychlicki. 2007. Applicability of the generalised D'Arcy and Watt model to description of water sorption on pineapple and other foodstuffs. Journal of Food Engineering 79:718-23.

Gouanvé, F., S. Marais, A. Bessadok, D. Langevin, and M. Métayer. 2007. Kinetics of water sorption in flax and PET fibers. European Polymer Journal 43:586-98.

Guo, X., L. Liu, J. Wu, J. Fan, and Y. Wu. 2018. Qualitatively and quantitatively characterizing water adsorption of a cellulose nanofiber film using micro-FTIR spectroscopy. RSC Advances 8:4214-20.

Guo, X., and Y. Wu. 2017. Characterizing molecular structure of water adsorbed by cellulose nanofiber film using in situ micro-FTIR spectroscopy. Journal of Wood Chemistry and Technology 37:383-92.

Haque, R., M. Saxena, S. C. Shit, and P. Asokan. 2015. Fibre-matrix adhesion and properties evaluation of sisal polymer composite. Fibers and Polymers 16:146-52.

Hill, C. A. S., A. Norton, and G. Newman. 2009. The water vapor sorption behavior of natural fibers. Journal of Applied Polymer Science 112:1524-37.

Himmel, S., and C. Mai. 2014. Effects of acetylation and formalization on the dynamic water vapor sorption behavior of wood. Holzforschung 69:633-43.

Kabir, M. M., H. Wang, K. T. Lau, and F. Cardona. 2012. Chemical treatments on plant-based natural fibre reinforced polymer composites: An overview. Composites Part B: Engineering 43:2883-92.

Kachrimanis, K., M. Noisternig, U. Griesser, and S. Malamataris. 2006. Dynamic moisture sorption and desorption of standard and silicified microcrystalline cellulose. European Journal of Pharmaceutics and Biopharmaceutics 64:307-15.

Kalia, S., B. S. Kaith, and I. Kaur. 2009. Pretreatments of natural fibers and their application as reinforcing material in polymer composites-A review. Polymer Engineering \& Science 49:1253-72.

Keating, B. A., C. A. S. Hill, D. Sun, R. English, P. Davies, and C. McCue. 2013. The water vapor sorption behavior of a galactomannan cellulose nanocomposite film analyzed using parallel exponential kinetics and the Kelvin-Voigt viscoelastic model. Journal of Applied Polymer Science 129:2352-59.

Kohler, R., R. Dück, B. Ausperger, and R. Alex. 2003. A numeric model for the kinetics of water vapor sorption on cellulosic reinforcement fibers. Composite Interfaces 10:255-76.

Laborel-Préneron, A., C. Magniont, and J.-E. Aubert. 2018. Hygrothermal properties of unfired earth bricks: Effect of barley straw, hemp shiv and corn cob addition. Energy and Buildings 178:265-78.

Mannan, K. M., and M. A. I. Talukder. 1997. Characterization of raw, delignified and bleached jute fibres by study of absorption of moisture and some mechanical properties. Polymer 38:2493-500.

Merzoud, M., and M. F. Habita. 2008. Elaboration de composite cimentaire à base de diss ampelodesma mauritanica. Afrique Science: Revue Internationale Des Sciences Et Technologie 4:231-45.

Nouri, M., I. Griballah, M. Tahlaiti, F. Grondin, and J. Beaugrand. 2019. Plant extraction and physicochemical characterizations of untreated and pretreated diss fibers (Ampelodesmos mauritanicus). Journal of Natural Fibers 1-11. published online Nov. 09, 2019. doi:10.1080/15440478.2019.1687062.

Patcharawijit, A., N. Choodum, and R. Yamsaengsung. 2019. Effects of superheated steam treatment on moisture adsorption and mechanical properties of pre-dried rubberwood. Drying Technology 37:1647-55.

Placet, V., A. Day, and J. Beaugrand. 2017. The influence of unintended field retting on the physicochemical and mechanical properties of industrial hemp bast fibres. Journal of Materials Science 52:5759-77.

Rong, M. Z., M. Q. Zhang, Y. Liu, G. C. Yang, and H. M. Zeng. 2001. The effect of fiber treatment on the mechanical properties of unidirectional sisal-reinforced epoxy composites. Composites Science and Technology 61:1437-47.

Roudier, A. 2012. Analyse multi-échelle du comportement hygro-mécanique des fibres de lin. Génie Mécanique, Université BLAISE PASCAL - Clermont II.

Saikia, D. 2010. Studies of water absorption behavior of plant fibers at different temperatures. International Journal of Thermophysics 31:1020-26.

Salmén, L., and P. A. Larsson. 2018. On the origin of sorption hysteresis in cellulosic materials. Carbohydrate Polymers 182:15-20.

Sarasini, F., J. Tirillò, G. Maffei, A. Zuorro, R. Lavecchia, F. Luzi, D. Puglia, L. Torre, and A. Maghchiche. 2019. Thermal and mechanical behavior of thermoplastic composites reinforced with fibers enzymatically extracted from Ampelodesmos mauritanicus. Polymer Engineering \& Science 59:2418-28.

Shi, J., and S. Avramidis. 2017. Water sorption hysteresis in wood: I review and experimental patterns - Geometric characteristics of scanning curves. Holzforschung 71:307-16. 
Sreekala, M. S., and S. Thomas. 2003. Effect of fibre surface modification on water-sorption characteristics of oil palm fibres. Composites Science and Technology 63:861-69.

Stamboulis, A., C. A. Baillie, and T. Peijs. 2001. Effects of environmental conditions on mechanical and physical properties of flax fibers. Composites: Part A 32:1105-15.

Sun, L.-M., F. Meunier, N. Brodu, and M.-H. Manero. 2016. Adsorption - Aspects théoriques. J2730 V2, Techniques de l'Ingénieur, 93288, Saint-Denis, France.

Thommes, M., K. Kaneko, A. V. Neimark, J. P. Olivier, F. Rodriguez-Reinoso, J. Rouquerol, and K. S. W. Sing. 2015. Physisorption of gases, with special reference to the evaluation of surface area and pore size distribution (IUPAC technical report). Pure and Applied Chemistry 87:1051-69.

Trabelsi, A., R. Belarbi, P. Turcry, and A. Ait-Mokhta. 2011. Characterization of water vapor desorption variability and its effects on drying simulation for an in-situ high performances concrete. Construction and Building Materials 141:140-51. 